
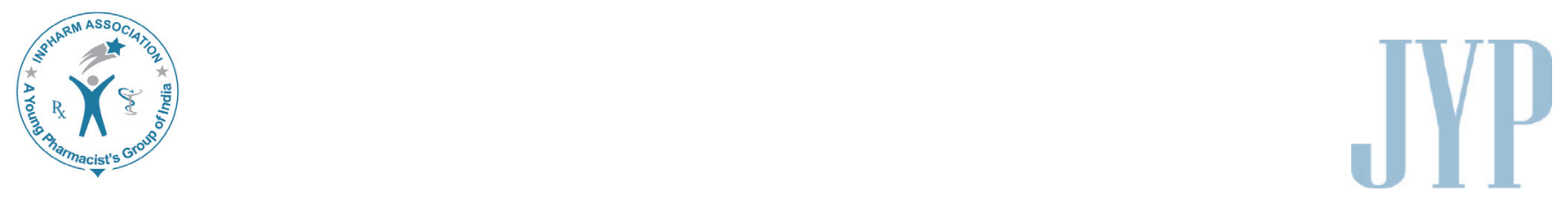

\title{
Optimization of Process Parameters for Development of Camptothecin Loaded Poly (Methacylic Acid-Co-Methyl Methyacrylate) Nanoparticles Using Plackett-Burman Factorial Design Methodology
}

\author{
Manikandan Mahalingam and Kannan Krishnamoorthy* \\ Department of Pharmacy, Annamalai University, Annamalai Nagar-608 002, Chidambaram, Tamil nadu, \\ India.
}

\begin{abstract}
Objective: The aim of the present study was to develop Camptothecin loaded poly (methacylic acid-co-methyl methyacrylate) nanoparticles and to optimize the process parameters for the preparation of polymeric nanoparticles using Plackett-Burman factorial design. The relationship between design factor and experimental data was evaluated. Method: In this study, Camptothecin loaded poly (methacylic acid-co-methyl methyacrylate) nanoparticles were prepared by nanoprecipitation method. The prepared nanoparticles were optimized using Plackett-Burman method. Critical formulation variables were optimized in this study in terms of their corresponding effects on the preparation of nanoparticles. The characterization of the optimized nanoformulations with respect to particle size distribution, particle morphology were carried out using malvern instrument and Transmission electron microscope (TEM). Results: Factorial design results have shown that (a) Except, $\beta$-cyclodextrin concentration, poloxamer concentration and the process all other parameters significantly influenced the average particle size; (b) Except, stirring time, stirring speed and stirring mode all other process parameters significantly influence the particle size uniformity; (c) Except, volume of organic phase and stirring speed all other process parameters significantly influence the surface area. Conclusion: The average particle size, particle size uniformity and surface area of the optimized formulation were found to be $99.29 \mathrm{~nm}, 0.242$ and $65.2 \mathrm{~m}^{2} \mathrm{~g}^{-1}$ respectively. Surface morphology examination has shown that the prepared nanoparticles were spherical in shape. Characterization of optimized formulation provided by evaluation of experimental data showed no significant difference between observed and predicted value.
\end{abstract}

Key words: Camptothecin, Nanoparticles, Optimization, Plackett-Burman design, Process parameters.

\begin{tabular}{|l|l|}
\hline \multicolumn{2}{|c|}{ Access this article online } \\
\hline \multirow{2}{*}{ Journal Sponsor } & $\begin{array}{l}\text { Website: } \\
\text { www.jyoungpharm.org }\end{array}$ \\
\cline { 2 - 2 } & $\begin{array}{l}\text { DOI: } \\
\text { www.phcognet }\end{array}$ \\
& \\
\hline
\end{tabular}

\section{INTRODUCTION}

*Address for correspondence:

Dr. Kannan Krishnamoorthy, Assistant Professor, Department of Pharmacy, Annamalai University, Annamalai Nagar-608 002,

Chidambaram, Tamil Nadu, India.E-mail:egkkannan@yahoo.co.in 


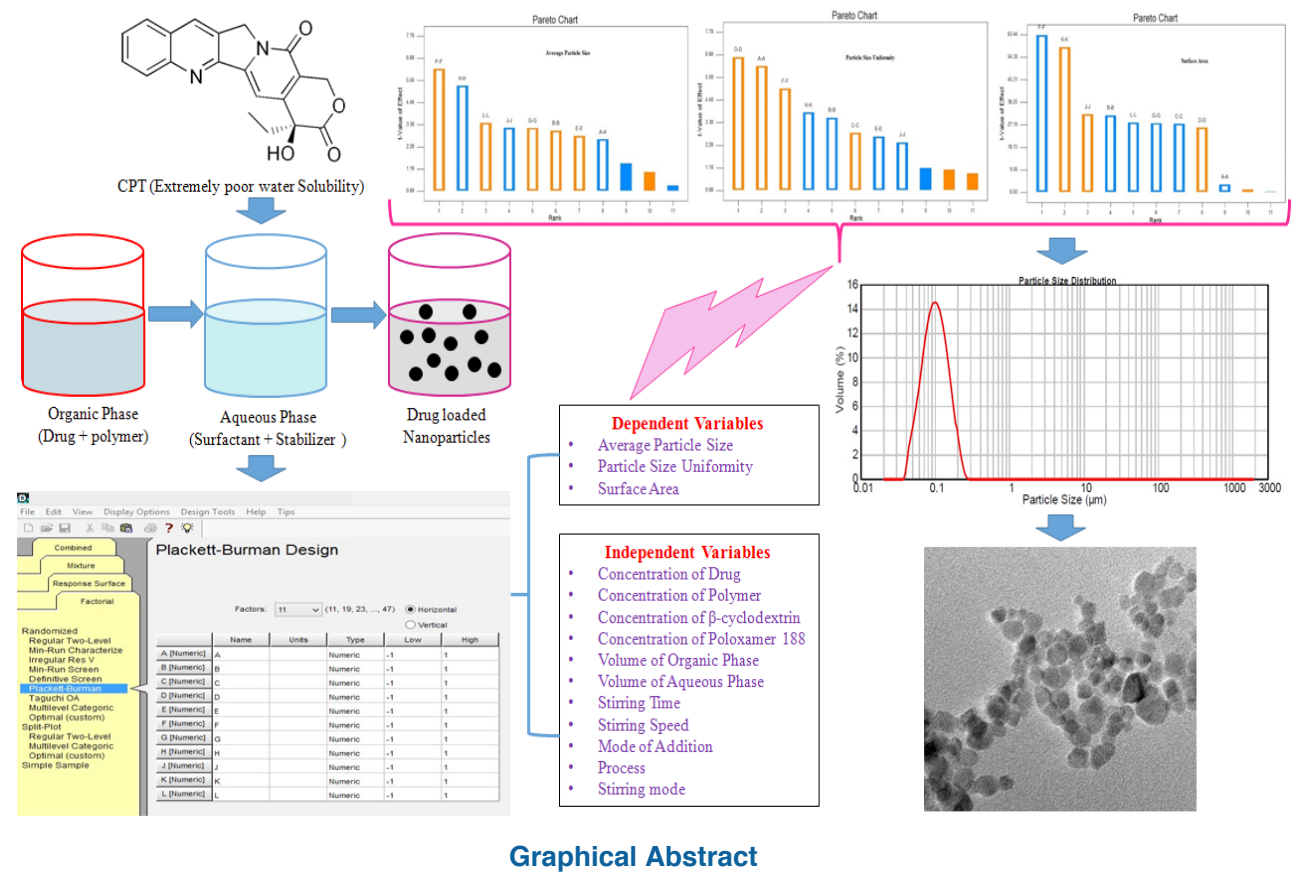

impeded the valuable clinical application of CPT in cancer therapy. ${ }^{3}$ This disadvantage remains the clinical hurdle of CPT in which low therapeutic efficacy and severe toxicity were displayed. ${ }^{7}$

Clinical application of CPT requires the targeting of the lactone form of drug to the site of action. In order to circumvent the limitation and to overcome the poor water solubility of lactone form and instability at biological $\mathrm{pH}$, various delivery carriers such as nanoparticles, microspheres, polymer conjugates, polymer micelles and dendrimers have been designed. ${ }^{7,8}$

Among the novel carriers, nanoparticles made by biodegradable polymers are the ideal vehicles to solve the problem of poor solubility. ${ }^{9}$ Prominently, nanoparticles have been broadly used because nanoparticle carriers enhance the drug's solubility and stability by encapsulating the hydrophobic drug in to the nano-size drug carrier. Broadly, the hydrophobic drug were covered with the hydrophilic and biocompatible polymer shells. ${ }^{10}$

It has been reported that anticancer drug encapsulated nanoparticles presented a promising therapeutic drug delivery system in cancer therapy. Other important advantages of nanoparticles includes simple preparation with polymer and it possess high stability either in fluid or during storage. ${ }^{9}$

The size and size distributions of nanoparticles are important to determine their interaction with the cell membrane and their penetration across the physiological drug barriers. The size of nanoparticles for crossing different biological barriers is dependent on the tissue, target site and circulation. The size of the nanoparticles also influences the particle size distribution of the nanoparticles. ${ }^{11,12}$

However, there are various methods used for the preparation of polymeric nanoparticles such as desolvation, dialysis, ionic gelation, nanoprecipitation, solvent evaporation, salting out, spray drying and supercritical fluid technology. ${ }^{13}$ However, nanoprecipitation is the most convenient and economical technique to fabricate polymeric nanoparticles. ${ }^{14,15}$

Though, it is a simple technique the quality of the prepared polymeric nanoparticles is influenced by various process parameters. The size of the particle is widely recognized as a critical attribute in determining the overall performance of the formulations. The average particle size, particle size uniformity and surface area were designated as the dependent variables. The role of particle size has become increasingly important in the case of poorly water soluble drugs. The surface area analysis was carried out to check the particles for agglomeration. The performance, stability and appearance of end product depends on the average particle size, particle size uniformity and surface area of the particles. ${ }^{16}$ Considering these parameters the dependent variables were selected.

The average particle size, particle size uniformity and surface area may be influenced by various parameters like concentration of drug, concentration of polymer, 
concentration of $\beta$-cyclodextrin, concentration of poloxamer 188, volume of organic phase, volume of aqueous phase, stirring time, stirring speed, mode of addition, process and stirring mode.

In order to optimize the process parameters and maintain repeatability screening design are performed. A two level mathematically derived multiple of four screening design popularly known as Plackett-Burman design was used. It was designed to improve the quality of the control process that could be used to study the effect of design parameters that could help us in making an intelligent decisions. ${ }^{17,18}$

The aim of the present study was to develop Camptothecin loaded poly (methacylic acid-co-methyl methyacrylate) nanoparticles and to optimize the process parameters using Plackett-Burman factorial design to understand the effect of various process parameters on the average particle size, particle size uniformity and surface area of the prepared nanoparticles.

\section{MATERIALS AND METHODS}

Camptothecin was commercially purchased from S.M Herbals, India. $\beta$-cyclodextrin and poloxamer (Grade 188) were procured from sigma Aldrich, India. Poly (methacylic acid-co-methyl methyacrylate) was obtained from Evonik Industries, India. All other chemicals and reagents used were of analytical grade.

\section{Development of Camptothecin loaded Poly (methacylic acid-co-methyl methyacrylate) Nanoparticles}

Camptothecin loaded poly (methacylic acid-co-methyl methyacrylate) nanoparticles was developed using nanoprecipitation method. ${ }^{19}$ Briefly, a specified quantity of Camptothecin and poly (methacylic acid-co-methyl methyacrylate) (anionic polymer) were dissolved in specified quantity of dimethyl sulphoxide (DMSO), which was transferred at once into the aqueous phase containing poloxamer 188 (non-ionic surfactant) and $\beta$-cyclodextrin (stabilizer) under mechanical stirrer (Remi, India). The aqueous phase turns into slightly milky with bluish opalescence spontaneously forming the polymeric nanoparticles. However, the stirring process was continued to evaporate the residual solvent present in the nanoformulaion and to aid the size reduction. ${ }^{20}$

\section{Experimental design}

Basically, the use of factorial design for the optimization of a procedure allows testing of a large number of factors concurrently and prevents the use of an enormous number of autonomous runs used in the traditional step-by-step approach. ${ }^{21,22}$ Traditional development of pharmaceutical formulations is an energy and time consuming approach, where one variable will be kept constant while others will be changing. Statistical experimental design, also known as design of experiments (DOE), is the methodology of how to conduct and plan experiments in order to extract the maximum amount of information with the lowest number of analysis. ${ }^{23}$ Screening design are the most powerful DOE technique that determine the most critical factors in the pharmaceutical development. DOE identifies optimal formulation and process conditions for these systems and provides understanding of the underlying relationship. A popular class of screening designs is the Plackett-Burman design (PBD) that screens large number of factors and identify critical one in a minimal number of run with good degree of accuracy. ${ }^{24}$ The use of Plackett-Burman experimental design allows for the study of multiple method factors in a systematic and logical way and leads to the identification of optimized conditions. The advantage of this design is that it allows a quick screening of all the factors through limited number of experiment. ${ }^{25}$

Generally, number of run needed to investigate the main effects are equal to $2^{\mathrm{n}}$ or multiple of 4 in Plackett-Burman designs instead of 2 as in the case of full factorial design. ${ }^{26}$ Plackett-Burman screening design with 12 experiments was constructed using software Design-Expert ${ }^{\circledR}$ (Version 9; Stat-Ease, Inc, USA). The linear equation of the model is as follows:

$$
Y=b_{0}+b_{1} X_{1}+b_{2} X_{2}+b_{3} X_{3}+b_{4} X_{4}+b_{5} X_{5}+\cdots+b_{n} X_{n}
$$

where $\mathrm{Y}$ is the response, $\mathrm{b}_{0}$ is the constant and $\mathrm{b}_{1}, \mathrm{~b}_{2} \ldots \mathrm{b}_{\mathrm{n}}$ are the coefficient of factor $\mathrm{X}_{1}, \mathrm{X}_{2} \ldots \mathrm{X}_{\mathrm{n}}$ (representing the effect of each factor ordered within $-1,+1){ }^{24}$

Nevertheless, the nanoparticle parameters such as average particle size (R1), particle size uniformiy (R2) and surface area (R3) depends on the process parameters. The process parameters which includes concentration of drug (A), concentration of polymer (B), concentration of $\beta$-cyclodextrin $(\mathrm{C})$ and concentration of poloxamer 188 (D), volume of organic phase (E), volume of aqueous phase $(\mathrm{F})$, stirring time $(\mathrm{G})$, stirring speed $(\mathrm{H})$, mode of addition $(\mathrm{J})$, process $(\mathrm{K})$ and stirring mode $(\mathrm{L})$. Hence, Plackett-Burman factorial design was used to optimize the process parameter at lower $(-)$ and higher $(+)$ level (Table 1). Twelve experimental trials (Table 2) involving 11 independent process parameters at higher and lower levels were generated using Design-Expert ${ }^{\mathbb{R}}$ (Version 9; 


\begin{tabular}{|c|c|c|c|}
\hline \multirow{2}{*}{ Factors } & \multirow{2}{*}{ Process Parameters } & \multicolumn{2}{|c|}{ Levels } \\
\hline & & Lower (-) & Higher (+) \\
\hline $\mathbf{X} 1$ & Concentration of Drug & $10 \mathrm{mg}$ & $12.5 \mathrm{mg}$ \\
\hline $\mathbf{X} 2$ & Concentration of Eudragit S 100 & $100 \mathrm{mg}$ & $125 \mathrm{mg}$ \\
\hline X3 & Concentration of $\beta-$ Cylcodextrin & $50 \mathrm{mg}$ & $62.5 \mathrm{mg}$ \\
\hline $\mathbf{X} 4$ & Concentration of Poloxamer 188 & $100 \mathrm{mg}$ & $125 \mathrm{mg}$ \\
\hline $\mathrm{X} 5$ & Volume of Organic Phase & $10 \mathrm{ml}$ & $12.5 \mathrm{ml}$ \\
\hline $\mathbf{X 6}$ & Volume of Aqueous Phase & $20 \mathrm{ml}$ & $25 \mathrm{ml}$ \\
\hline $\mathbf{x 7}$ & Stirring Time & 50 mins & 70 mins \\
\hline $\mathbf{X 8}$ & Stirring Speed & 500 rpm & $1000 \mathrm{rpm}$ \\
\hline X9 & Mode of Addition & Atonce & Syringe \\
\hline $\mathbf{X} 10$ & Process & Or. to Aq. & Aq. to Or. \\
\hline $\mathrm{X} 11$ & Stirring Mode & Blade & Homogenizer \\
\hline
\end{tabular}

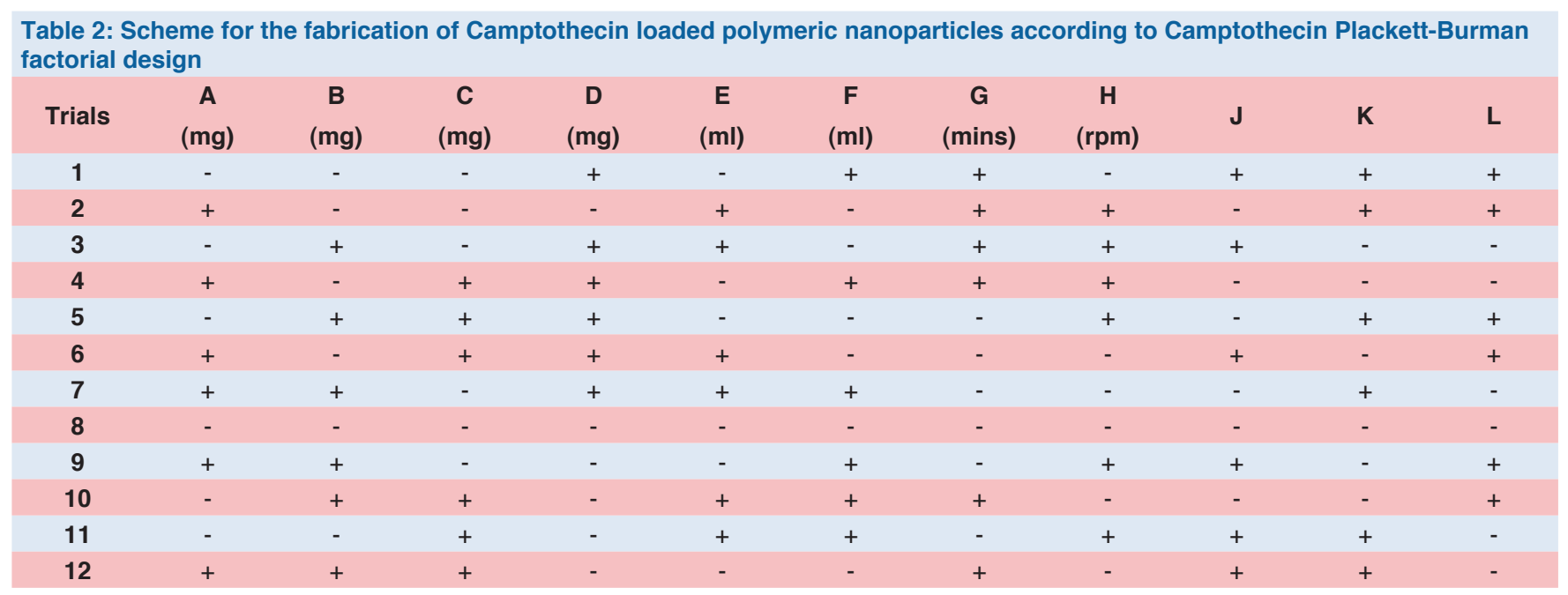

A: Concentration of Drug;B:Concentration of Polymer; $\mathrm{C}$ : Concentration of $\beta$-Cyclodextrin; $\mathrm{D}$ : Concentration of Poloxamer 188; $\mathrm{E}$ : Volume of Organic Phase; F: Volume of Aqueous Phase; G: Stirring Time; H:Stirring Speed; J:Mode of Addition; K:Process; L:Stirring Mode.

Table 3: Optimized formula for fabrication of Camptothecin loaded poly (methacylic acid-co-methyl methyacrylate) nanoparticles

\begin{tabular}{ccccccccccccc} 
& \multicolumn{1}{c}{ Trials } & $\mathbf{A}$ & $\mathbf{B}$ & $\mathbf{C}$ & $\mathbf{D}$ & $\mathbf{E}$ & $\mathbf{F}$ & $\mathbf{G}$ & $\mathbf{H}$ & $\mathbf{J}$ & $\mathbf{K}$ & $\mathbf{L}$ \\
& $(\mathbf{m g})$ & $(\mathbf{m g})$ & $(\mathbf{m g})$ & $(\mathbf{m g})$ & $(\mathbf{m l})$ & $(\mathbf{m l})$ & $(\mathbf{m i n s})$ & $(\mathbf{r p m})$ & Atonce & Or.toAq. & Blade
\end{tabular}

Or=Organic Phase; $\mathrm{Aq}=$ Aqueous Phase.

Stat-Ease, Inc, USA). Prepared polymeric nanoparticles were characterized for average particle size, particle size uniformity and surface area using malvern instrument (Metasizer).

\section{Fabrication of Camptothecin loaded Poly (methacylic acid-co-methyl methyacrylate) nanoparticles}

Camptothecin loaded poly (methacylic acid-comethyl methyacrylate) nanoparticles were prepared by nanoprecipitation method as per the scheme and the observed responses of Plackett-Burman are shown in Table 3. About, $10 \mathrm{mg}$ of drug along with $100 \mathrm{mg}$ of polymer were dissolved in $10 \mathrm{ml}$ of dimethyl sulphoxide. The prepared organic phase was transferred at once into $500 \mathrm{ml}$ beaker containing $50 \mathrm{mg}$ of $\beta$-cyclodextrin, $100 \mathrm{mg}$ of poloxamer 188 and $20 \mathrm{ml}$ of distilled water under mechanical stirring (Remi, India) at $500 \mathrm{rpm}$. Polymeric nanoparticles were formed spontaneously but the stirring process is continued for 50 mins to aid the size reduction and to evaporate the residual solvents. The prepared polymeric nanoparticles were characterized for average particles size, particle size uniformity and surface area using mastersizer (Malvern Instruments, UK) and the surface morphology of the optimized trial was determined by transmission electron microscopy (Hitachi H7500, India) at 20,000 magnifications. 


\begin{tabular}{|c|c|c|c|}
\hline Trials & $\begin{array}{l}\text { Average Particle Size } \\
\qquad(\mathrm{nm} \pm \mathrm{SD})\end{array}$ & $\begin{array}{l}\text { Particle Size Uniformity } \\
\qquad( \pm \mathrm{SD})\end{array}$ & $\begin{array}{c}\text { Surface Area } \\
\left(\mathrm{m}^{2} \mathrm{~g}^{-1} \pm \mathrm{SD}\right)\end{array}$ \\
\hline 1 & $272 \pm 0.58$ & $0.272 \pm 0.01$ & $53.5 \pm 0.57$ \\
\hline 2 & $103 \pm 0.27$ & $0.246 \pm 0.03$ & $63.4 \pm 0.26$ \\
\hline 3 & $105 \pm 0.32$ & $0.243 \pm 0.02$ & $62.4 \pm 0.54$ \\
\hline 4 & $132.314 \pm 0.38$ & $0.394 \pm 0.02$ & $0.463 \pm 0.78$ \\
\hline 5 & $108 \pm 0.47$ & $0.254 \pm 0.03$ & $60.5 \pm 0.35$ \\
\hline 6 & $117 \pm 0.52$ & $0.298 \pm 0.01$ & $57.5 \pm 0.54$ \\
\hline 7 & $264.938 \pm 0.55$ & $0.287 \pm 0.02$ & $31.6 \pm 0.65$ \\
\hline 8 & $102 \pm 0.25$ & $0.244 \pm 0.01$ & $63.9 \pm 0.21$ \\
\hline 9 & $123.51 \pm 0.54$ & $0.272 \pm 0.02$ & $0.503 \pm 0.64$ \\
\hline 10 & $1175.06 \pm 1.24$ & $0.251 \pm 0.03$ & $0.00589 \pm 1.85$ \\
\hline 11 & $102 \pm 0.54$ & $0.244 \pm 0.02$ & $63.6 \pm 0.21$ \\
\hline 12 & $102 \pm 0.68$ & $0.244 \pm 0.02$ & $63.6 \pm 0.53$ \\
\hline
\end{tabular}

Briefly, prepared Camptothecin loaded polymeric nanoparticles formulation was added drop-wise in to the water maintained in the sample dispersion unit of particle size analyser, where the nanoparticles scattered using single shaft pump and stirrer and re-circulated continuously around the measurement zone of the particle size analyser. The prepared Camptothecin loaded polymeric nanoparticles were dropped onto formvar-coated copper grids and air dried. The samples were then negatively stained with $1 \%$ uranyl acetate for 10 minutes and air dried again. The samples were then imaged using transmission electron microscope..$^{27,28}$

Average particle size and surface area determine the performance of nanoparticles which includes solubility, dissolution, stability, circulation half-life, cellular uptake, drug release and bio-distribution. Hence, average particle size less than $200 \mathrm{~nm}$ and surface area above $50 \mathrm{~m}^{2} \mathrm{~g}^{-1}$ are required for maximum performance of the prepared polymeric nanoparticles. Similarly, particle size uniformity determines the consistency of performance of the prepared polymeric nanoparticles. Particle size uniformity between 0.1-0.25 indicates narrow distribution and value above 0.5 indicates a broad distribution..$^{29,30}$

\section{RESULTS AND DISCUSSION}

\section{Development of Camptothecin loaded poly (methacylic acid-co-methyl methyacrylate) nanoparticles}

Camptothecin loaded polymeric nanoparticles were developed using the nanoprecipitation method. During nanoprecipitation method, addition of organic phase in to the aqueous phase leads to rapid miscibility of dimethyl sulphoxide with water results in spontaneous growth of nanoparticles, which is initially controlled by stirring followed by adsorption of poly (methacylic acidco-methyl methyacrylate), which acts as the barrier and inhibits the further growth of nanoparticles. Prepared polymeric nanoparticles were characterized for average particle size, particle size uniformity and surface area (Table 4). Regardless of its simplicity, nanoprecipitation method involves many processes, which influence the quality of nanoparticles. Hence we have implemented Plackett-Burman factorial design to optimize the process parameters.

\section{Effect of process parameters on the average particle size}

The recital of the prepared polymeric nanoparticles such as solubility, dissolution, drug release and cellular uptake are influenced by the average particle size. So it is essential to develop a polymeric nanoparticles with least average particle size. ${ }^{29,30}$ Analysis of variance has shown that the process parameters have significant effect (Prob. F, 0.0240) on the average particle size (Table 5). Except, concentration of $\beta$-cyclodextrin, concentration of poloxamer 188 and the process all other parameters significantly influenced the average particle size (Figure 1). In the figure, orange colour indicates the process parameter has positive effect and blue colour column indicates the negative effect on the average particle size. The white column inside both orange and blue columns indicates that the parameters have significant effect on the average particle size.

Process parameters such as volume of organic phase and aqueous phase, concentration of drug and polymer, mode of addition, stirring time, stirring speed and stirring mode have favourable effect on the average particle size, whereas concentration of $\beta$-cyclodextrin, concentration of poloxamer 188 and the process have inverse relationship with the average particle size (Figure 1). Moreover, the 


\begin{tabular}{|c|c|c|c|c|c|c|}
\hline Variables & Source & Sum of Square & $D_{f}$ & Mean of Square & F Ratio & Prob $>F^{*}$ \\
\hline \multirow{3}{*}{$\begin{array}{c}\text { Average Particle } \\
\text { Size }\end{array}$} & Model & 5.69 & 8 & 0.71 & \multirow{3}{*}{14.97} & \multirow{3}{*}{0.0240} \\
\hline & Residual & 0.14 & 3 & 0.048 & & \\
\hline & C. Total & 5.84 & 11 & - & & \\
\hline \multirow{3}{*}{$\begin{array}{l}\text { Particle Size } \\
\text { Uniformity }\end{array}$} & Model & 0.21 & 8 & 0.026 & \multirow{3}{*}{18.94} & \multirow{3}{*}{0.0171} \\
\hline & Residual & 0.004182 & 3 & 0.001394 & & \\
\hline & C. Total & 0.22 & 11 & - & & \\
\hline \multirow{3}{*}{ Surface Area } & Model & 100.79 & 9 & 11.20 & \multirow{3}{*}{1386.07} & \multirow{3}{*}{0.0007} \\
\hline & Residual & 0.96 & 2 & 0.008079 & & \\
\hline & C. Total & 100.80 & 11 & - & & \\
\hline
\end{tabular}

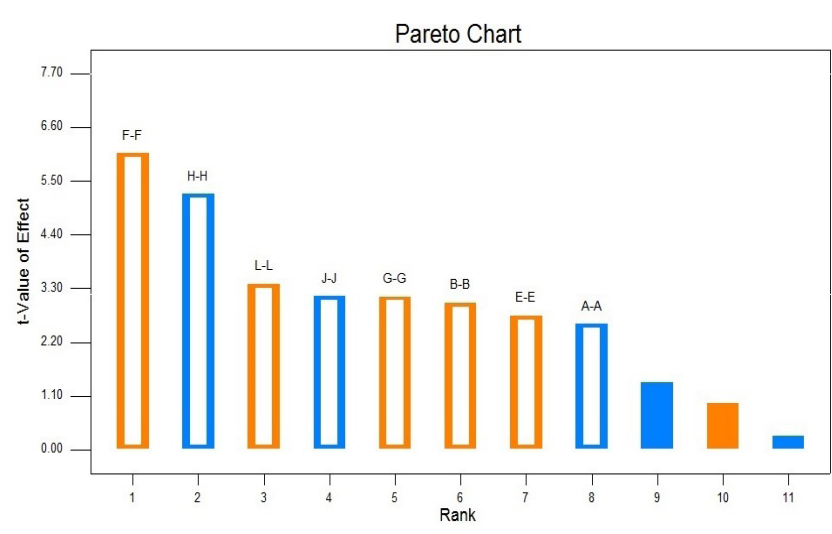

Figure 1: Plackett-Burman plot for the average particle size

Orange colour indicates the parameter has positive effectand blue colour column indicates the negative effecton the average particle size. The white columninside the orange columns indicates that the parameters has significant effect on the average particle size.

observed average particle size was comparable with predicted values of Plackett-Burman factorial design (Table 6).

\section{Effect of process parameters on the particle size uniformity}

The consistency of the prepared polymeric nanoparticles were determined by the particle size uniformity. Hence, it is essential to develop polymeric nanoparticles with the particle size uniformity between $0.1-0.25 .{ }^{29,30}$ Analysis of variance has shown that the process parameters have significant effect (Prob. F, 0.0171) on the particle size uniformity (Table 5). Except, stirring time, stirring speed and stirring mode all other process parameters significantly influenced the particle size uniformity (Figure 2). In the figure, orange colour indicates the parameter has positive effect and blue colour column indicates the negative effect on the particle size uniformity. The white column inside the orange and blue colour indicates that the parameters have significant effect on the particle size uniformity.

Process parameters such as concentration of drug, polymer, $\beta$-cyclodextrin and poloxamer 188, volume of organic

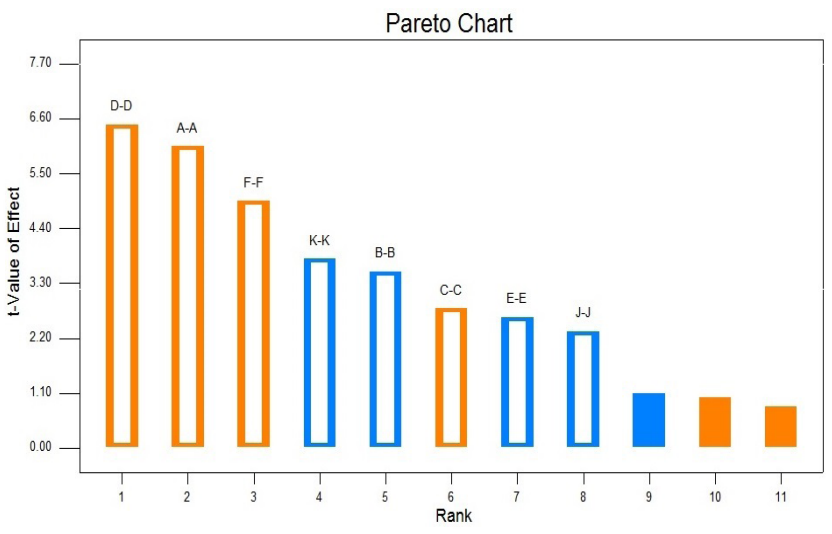

Figure 2: Plackett-Burman plot for the particle size uniformity

Orange colourindicatesthe parameterhas positive effectand blue colourcolumn indicates the negativeeffecton the average particle size. The white columninside the orange columns indicates that the parameters has significant effect on the average particle size.

phase and aqueous phase, mode of addition and process have favourable effect on the particle size uniformity, whereas stirring time, stirring speed and stirring mode have inverse relationship with the particle size uniformity (Figure 2). Moreover, the observed particle size uniformity was comparable with predicted values of Plackett-Burman factorial design (Table 6).

\section{Effect on process parameters on the surface area}

The biological effect of the prepared polymeric nanoparticles depends on the surface area of the nanoparticles. Hence, it is essential to develop polymeric nanoparticles with the surface area above $50 \mathrm{~m}^{2} \mathrm{~g}^{-1} \cdot{ }^{29,30}$ Analysis of variance has shown that the process parameters have significant effect (Prob. F, 0.0007) on the surface area (Table 5). Except, volume of organic phase and stirring speed all other parameters significantly influence the surface area (Figure 3). In the figure, orange colour indicates the parameter has positive effect and blue colour column indicates the negative effect on the surface area. The white column inside the orange and blue colour indicates that the parameters have significant effect on the surface area. 


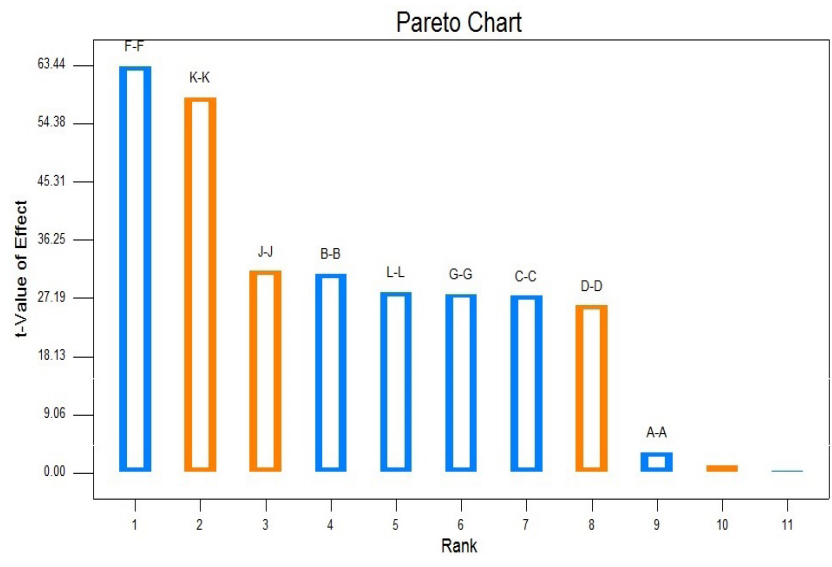

Figure 3: Plackett-Burman plot for the surface area

Orange colourindicatesthe parameterhas positive effectand bluecolourcolumn indicates the negative effectontheaverage particlesize. The white columninside the orange columns indicates that the parameters has significant effect on the average particle size.
Process parameters such as concentration of drug, polymer, $\beta$-cyclodextrin and poloxamer 188, volume of aqueous phase, stirring time, mode of addition, process and stirring mode have favourable effect on the surface area, whereas volume of organic phase and stirring speed have inverse relationship with the surface area (Figure 3). Moreover, the observed surface area was comparable with predicted values of Plackett-Burman factorial design (Table 6).

The optimized formula (with desirability: 1.000) for the fabrication of Camptothecin loaded polymeric nanoparticles was displayed in RAMPS format (Figure 4). Camptothecin loaded polymeric nanoparticles were prepared using the final optimized formula form PlackettBurman factorial design. About, $10 \mathrm{mg}$ of drug along with $100 \mathrm{mg}$ of polymer were dissolved in $10 \mathrm{ml}$ of DMSO. The prepared organic phase was transferred at once

\begin{tabular}{|c|c|c|c|c|c|c|c|c|c|}
\hline \multirow[t]{2}{*}{$\mathbf{F}$} & \multicolumn{3}{|c|}{ Average Particle Size } & \multicolumn{3}{|c|}{ Particle size Uniformity } & \multicolumn{3}{|c|}{ Surface Area } \\
\hline & Observed & Predicted & \%RE & Observed & Predicted & $\%$ RE & Observed & Predicted & \%RE \\
\hline 1 & 5.61 & 5.77 & -2.77 & -1.30 & -1.29 & 0.77 & 3.98 & 4.00 & -0.50 \\
\hline 2 & 4.63 & 4.77 & -2.93 & -1.40 & -1.41 & -0.71 & 4.15 & 4.13 & 0.48 \\
\hline 3 & 4.65 & 4.65 & 0 & -1.41 & -1.45 & -2.75 & 4.13 & 4.11 & 0.48 \\
\hline 4 & 4.89 & 4.75 & 2.94 & -0.93 & -0.96 & -3.12 & -0.77 & -0.82 & -6.09 \\
\hline 5 & 4.68 & 4.73 & -1.05 & -1.37 & -1.36 & 0.73 & 4.10 & 4.06 & 0.98 \\
\hline 6 & 4.76 & 4.63 & 2.80 & -1.21 & -1.18 & 2.54 & 4.05 & 4.10 & -1.21 \\
\hline 7 & 5.58 & 5.75 & -2.95 & -1.25 & -1.24 & 0.81 & 3.45 & 3.50 & -1.43 \\
\hline 8 & 4.62 & 4.58 & 0.87 & -1.41 & -1.40 & 0.71 & 4.16 & 4.18 & -0.48 \\
\hline 9 & 4.82 & 4.77 & 1.04 & -1.30 & -1.29 & 0.77 & -0.69 & -0.73 & -5.48 \\
\hline 10 & 7.07 & 6.90 & 2.40 & -1.38 & -1.37 & 0.73 & -5.13 & -5.09 & 0.785 \\
\hline 11 & 4.62 & 4.63 & -0.21 & -1.41 & -1.42 & -0.70 & 4.15 & 4.13 & 0.48 \\
\hline 12 & 4.62 & 4.63 & -0.21 & -1.41 & -1.42 & -0.70 & 4.15 & 4.18 & -0.72 \\
\hline
\end{tabular}

F=Formulation; \%RE=Percentage Relative Error

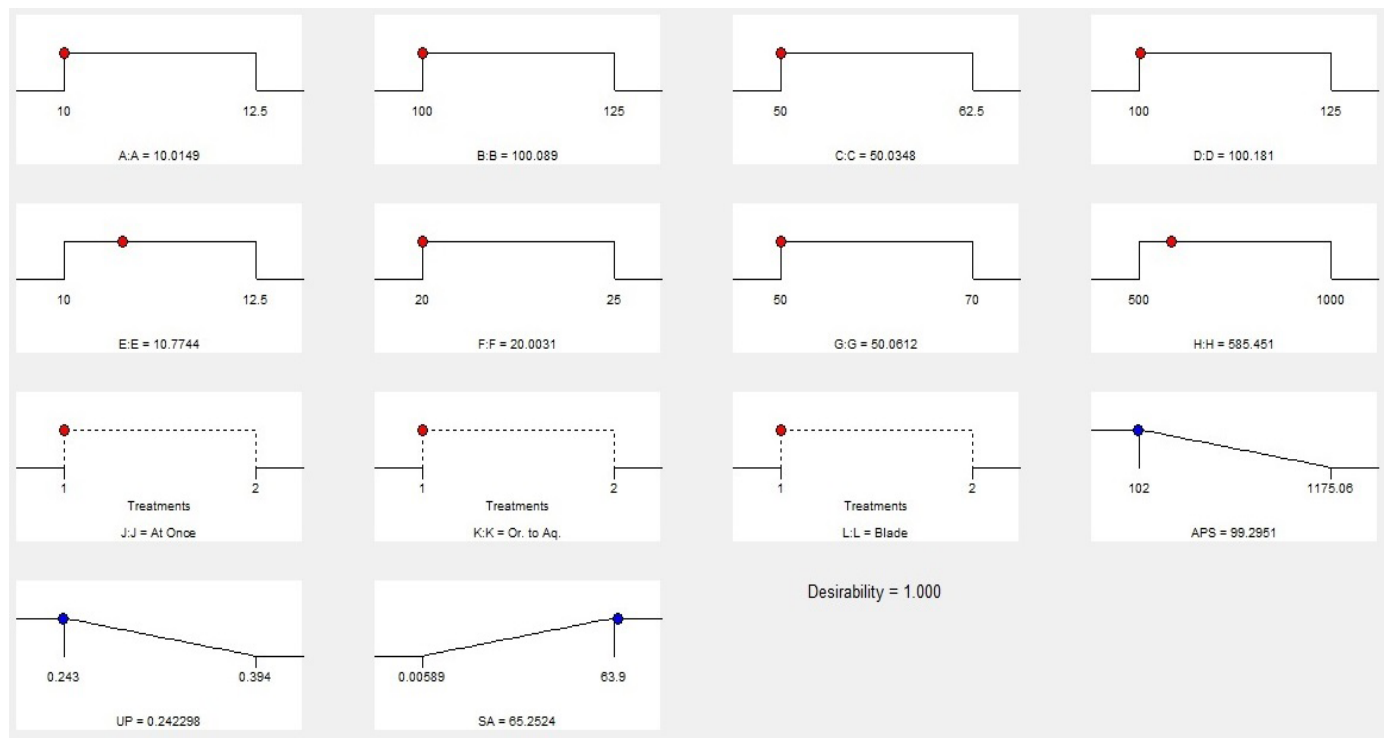

Figure 4: RAMPS format of optimized formula for the fabrication of poly (methacylic acid-co-methyl methyacrylate) based nanoparticulate drug delivery system 

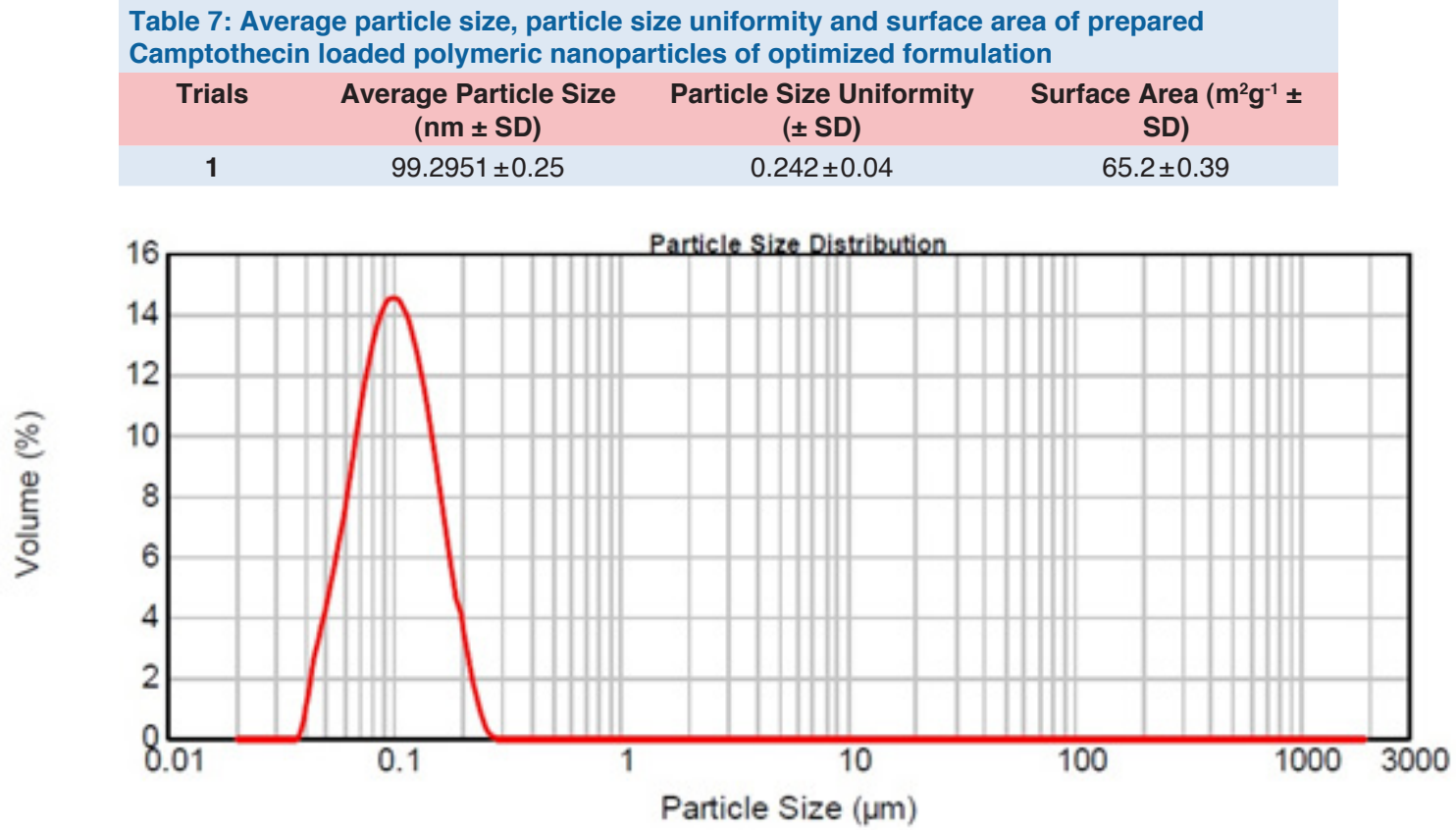

Figure 5: Particle size spectrum of prepared Camptothecin loaded polymeric nanoparticles

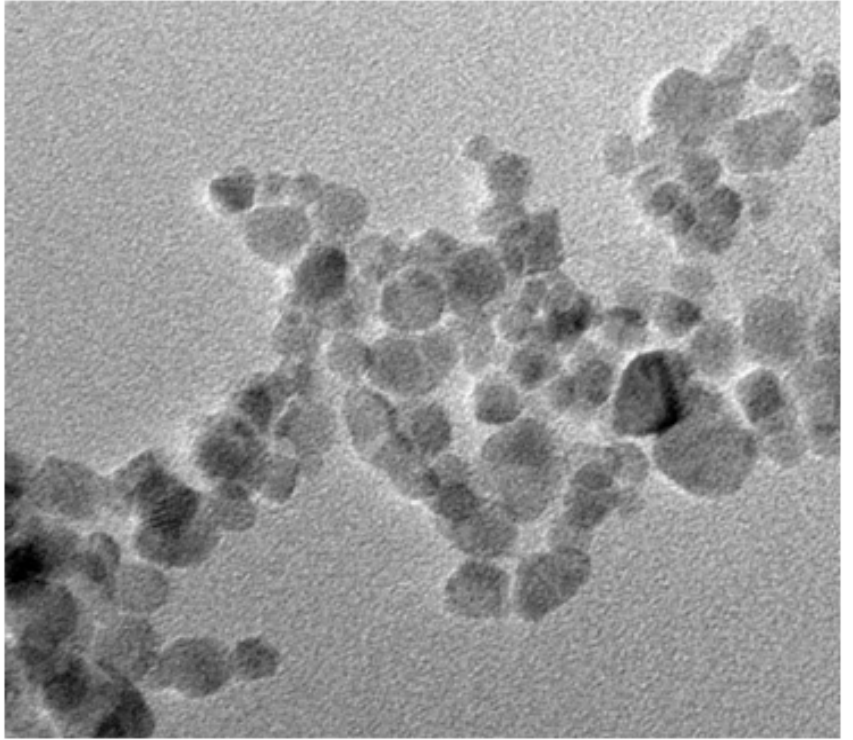

Figure 6: TEM image of prepared Camptothecin loaded polymeric nanoparticles

into $500 \mathrm{ml}$ beaker containing $50 \mathrm{mg}$ of $\beta$-cyclodextrin, $100 \mathrm{mg}$ of poloxamer 188 and $20 \mathrm{ml}$ of distilled water under mechanical stirring (Remi, India) at $500 \mathrm{rpm}$ for 50 mins. Prepared drug loaded polymeric nanoparticles were characterized for average particle size, particle size uniformity and surface area. The characterized results were summarized in Table 7 and Figure 5.

The basic function of nanoparticles (i.e.,) release of drug from polymer matrix, transport of particles in the body, internalization of drug depends on the surface morphology of the nanoparticles. Transmission electron microscope was used to image the prepared drug loaded polymeric nanoparticles and found to be spherical in shape (Figure 6).

\section{CONCLUSION}

In the present study, Camptothecin loaded poly (methacylic acid-co-methyl methyacrylate) nanoparticles were prepared using nanoprecipitation method. Plackett-Burman factorial design was used to investigate the impact of critical factors on the response properties. Plackett-Burman screening design helped in identifying the significant parameters that affected the response variables. Screening designs used in the early stages of research and development helps the researcher to identify the significant factors for a largescale simulation with a relatively small number of runs. Final optimization was achieved using a Plackett-Burman design which involves eleven independent variables at lower and higher levels generated by design expert software. The prepared nanoparticles were characterized for the average particle size, particle size uniformity and surface area. Average particle size $<200 \mathrm{~nm}$, particle size uniformity between $0.1-0.25$ and surface area above $50 \mathrm{~m}^{2} \mathrm{~g}^{-1}$ were used to evaluate the quality of the prepared nanoparticles. Morphological study of particles revealed that the formation of non-aggregated, uniformly sized, to oval shape particles with smooth surfaces. The experimental results were found to be in good agreement with the predicted data analysed by the Plackett-Burman method. 


\section{ACKNOWLEDGEMENT}

The authors are thankful to UGC, Government of India, for providing UGC-BSR Fellowship.

\section{CONFLICT OF INTEREST}

The authors declare that there are no conflicts of interest.

\section{ABBREVIATION}

$\begin{array}{ll}\text { TEM: } & \text { Transmission electron microscope } \\ \text { CPT: } & \text { Camptothecin } \\ \text { DNA: } & \text { Deoxyribonucleic acid } \\ \text { DMSO: } & \text { Dimethyl sulphoxide } \\ \text { DOE: } & \text { Design of Experiments } \\ \text { PBD: } & \text { Plackett-Burman design }\end{array}$

\section{Highlights of Paper}

- Camptothecin (CPT) is a quinoline alkaloid isolated from Camptotheca acuminate with a promising antitumor activity for a wide range of cancers.

- Extremely poor water solubility have impeded the valuable clinical application of CPT in cancer therapy.

- Among the novel carriers, nanoparticles made by biodegradable polymers are the ideal vehicles to solve the problem of poor solubility.

- Camptothecin loaded poly (methacylic acid-co-methyl methyacrylate) nanoparticles were prepared by nanoprecipitation method and were optimized using Plackett-Burman method.

- Critical formulation variables were optimized in this study in terms of their corresponding effects on the preparation of nanoparticles.

- The average particle size, particle size uniformity and surface area of the optimized formulation were found to be $99.29 \mathrm{~nm}, 0.242$ and $65.2 \mathrm{~m}^{2} \mathrm{~g}^{-1}$ respectively.

- Characterization of optimized formulation provided by evaluation of experimental data showed no significant difference between observed and predicted value.

\section{Author Profile}

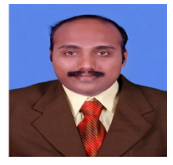

- Dr. Kannan Krishnamoorthy: Presently working as an Assistant Professor in Department of Pharmacy, Annamalai University, Annamalai Nagar. He is an accomplished researcher and eminent teacher with the experience in the area of Pharmaceutics. He had organized many national and international conferences. He has supervised a number of postgraduate research students in developing pharmaceutical dosage forms in collaboration with reputed pharmaceutical industries His current area of research involves drug delivery system using nanotechnology. He has published more than 36 review and research articles in peer reviewed journals.

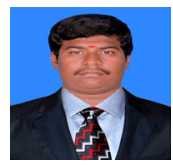

- Manikandan Mahalingam: Is a doctoral student at Department of Pharmacy, Annamalai University, Annamalai Nagar. His doctoral research is focused on developing a nanoparticulate drug delivery system for the management of colon cancer.

\section{REFERENCES}

1. Nilesh Patankar, Dawn Waterhouse. Nano-particulate Drug Delivery Systems for Camptothecins. Cancer Ther. 2012; 8(8): 90-104.

2. Wang LM, Li QY, Zu YG, Fu YJ, Chen LY, Lv HY, et al. Antiproliferative and pro-apoptotic effect of CPT13, a novel Camptothecin analog, on human colon cancer HCT8 cell line. Chem-Biol Interact. 2008; 176(2): 165-72.

3. Xian-ping Liu, Sheng-tao Zhou, Xing-yi Li, Xian-cheng Chen, Xia Zhao, Zhi-yong Qian, et al. Anti-tumor activity of N-trimethyl chitosan-encapsulated Camptothecin in a mouse melanoma model. J Exp Clin Canc Res. 2010; 29(1): 76.

4. Hsiang YH, Hertzberg R, Hecht S, Liu LF. Camptothecin induces protein-linked DNA breaks via mammalian DNA topoisomerase I. J Biol Chem. 1985; 260(27): 14873-88.

5. Liu LF. DNA topoisomerase poisons as antitumor drugs. Annu Rev Biochem. 1989; 58(1): 351-75.

6. Berrada M, Serreqi A, Dabbarha F, Owusu A, Gupta A, Lehnert S. A novel non-toxic Camptothecin formulation for cancer chemotherapy. Biomaterials 2005; 26(14): 2115-20.

7. Nguyen-Van Cuong, Ming Fa Hsieh, Chun-Ming Huang. Recent development in nano-sized dosage forms of plant alkaloid Camptothecin-derived drugs. Recent Pat Anticancer Drug Discov. 2009; 4(3): 254-61.
8. Thomas CJ, Rahier NJ, Hecht SM. Camptothecin: Current perspectives. Bioorg Med Chem. 2004; 12(7): 1585-604.

9. Wei Shi, Zhan-jie Zhang, Yin Yuan, En-ming Xing, You Qin, Zhen-jun Peng, et al. Optimization of Parameters for Preparation of Docetaxel-loaded PLGA Nanoparticles by Nanoprecipitation Method. J Huazhong Univ Sci Technol Med Sci. 2013; 33(5): 754-8.

10. Kyung Hyun Min, Kyeongsoon Park, Yoo-Shin Kim, Sang Mun Bae, Seulki Lee, Hyung Gon Jo, et al. Hydrophobically modified glycol chitosan nanoparticles-encapsulated Camptothecin enhance the drug stability and tumor targeting in cancer therapy. J. of Control Release 2008; 127(3): 208-18.

11. Zhengyu Deng, Ruiping Zhao, Liang-Chang Dong, Geoff Wong Characterization of Nanoparticles for Drug Delivery Applications. Microsc Microanal. 2005; 11(Suppl 2): 1934-5.

12. Brannon-Peppas L, Blanchette JO. Nanoparticle and targeted systems for cancer therapy. Adv Drug Deliv Rev. 2004; 56(1): 1649-59.

13. Sailaja A, Amareshwar P, Chakravarty P. Different techniques used for the preparation of nanoparticles using natural polymers and their application. Int J Pharm Pharm Sci. 2011; 3(suppl 2): 45-50.

14. Khayata N, Abdelwahed W, Chehna MF, Charcosset C, Fessi $\mathrm{H}$. Preparation of vitamin $\mathrm{E}$ loaded nanocapsules by the 
nanoprecipitation method: From laboratory scale to large scale using a membrane contactor. Int J Pharm. 2012; 423(2): 419-27.

15. Manikandan Mahalingam, Kannan Krishnamoorthy. Selection of a Suitable Method for the Preparation of Polymeric Nanoparticles: Multi-Criteria Decision Making Approach. Adv Pharm Bull. 2015; 5(1): 57-67.

16. Rohrs BR, Amidon GE, Meury RH, Secrest PJ, King HM, Skoug CJ. Particle size limits to meet USP content uniformity criteria for tablet and capsules. J Pharm Sci. 2006; 95(5): 1049-59.

17. Vanaja K, Shobha Rani RH. Design of Experiments: concept and applications of Plackett-Burman Design. Clin Res Regul Aff. 2007; 24(1): 1-23.

18. Yannis LL. A Plackett-Burnam screening design directs the efficient formulation of multicomponent DRV liposomes. J Pharm Biomed Anal. 2001; 26(2): 255-63.

19. Mora-Huertas CE, Fessi H, Elaissari A. Polymer based nanocapsules for drug delivery. Int J Pharm. 2010; 385(1-2): 113-42.

20. Moorthi Chidambaram, Kathiresan Krishnasamy. Development of Dimethylaminoehtyl Methacrylate based nanoparticlate Drug delivery system using nanoprecipitation method and Optimization of process parameters using Plackett-Burman factorial design. Nano Biomed Eng. 2014; 6(1): 19-30.

21. Mohammad-Ali Shahbazia, Mehrdad Hamidi, Soliman MohammadiSamani. Preparation, optimization, and in vitro in vivo ex vivo characterization of chitosan-heparin nanoparticles: drug-induced gelation. J Pharm Pharmacol. 2013; 65(8): 1118-33.

22. Jose S, Fangueiro JF, Smitha J, Cinu TA, Chacko AJ, Premaletha $\mathrm{K}$, et al. Cross-linked chitosan microspheres for oral delivery of insulin: Taguchi design and in vivo testing. Colloids Surf B Bio interfaces 2012; 92(4): 175-9.

23. Decaestecker TN, Lambert WE, Peteghem Carlos HV, Deforce D, Van Bocxlaer JF. Optimization of solid-phase extraction for a liquid chromatographic-tandem mass spectrometric general unknown screening procedure by means of computational techniques. J Chrom A. 2004; 1056(1): 57-65.

24. Ziyaur Rahman, Ahmed S, Zidan, Muhammad Habib J, Mansoor Khan A. Understanding the quality of protein loaded PLGA nanoparticles variability by Plackett-Burman design. Int J Pharm. 2010; 389(1-2): 186-94.

25. Weiyong Li, Henrik Rasmussen T. Strategy for developing and optimizing liquid chromatography methods in pharmaceutical development using computer-assisted screening and PlackettBurman experimental design. J Chrom A. 2003; 1016(2): 165-80.

26. Plackett RL, Burman JP. The design of optimum multifactorial experiments. Biometrika 1946; 33(4): 305-25.

27. Champion JA, Katare YK, Mitragotri S. Particle shape: a new design parameter for micro- and nanoscale drug delivery carriers. J. Control Release 2007; 121(1-2): 3-9.

28. YaShu Yin, DaWei Chen, Ming Xi Qiao, Zhe Lu, HaiYang $\mathrm{Hu}$. Preparation and evaluation of lectin-conjugated PLGA nanoparticles for oral delivery of thymopentin. J. Control Release 2006; 116(3): 337-45.

29. Xie H, Smith JW. Fabrication of PLGA nanoparticles with a fluidic nano-precipitation system. Nanobiotechnology 2010; 8(1): 1-7.

30. Lakshmi P, Ashwini KG. Nanosuspension technology: A review. Int J Pharm Sci. 2010; 2(4): 35-40. 